\title{
LICENCIATURA: escolha ou falta de opção
}

\author{
Evelyn Jeniffer de Lima Toledo' \\ Henrique do Nascimento Coutinho2
}

\section{RESUMO}

A princípio, ninguém discorda que a educação é essencial para o progresso do país. No entanto, essa preocupação não se traduz na valorização da profissão docente seja no quesito condições de trabalho ou salarial. Apesar de todos os problemas, ainda há alunos que ingressam em cursos de licenciatura, permanecem e se tornam professores por todo o país nas mais diversas instituições de ensino. Assim, o objetivo deste artigo foi analisar o que motiva os discentes a permanecerem em um curso de Licenciatura em Química na UnB. Para responder à questão de pesquisa, foi utilizada a metodologia quantitativa tendo sido desenvolvido um questionário baseado na teoria da Autodeterminação, do tipo Likert. Como resultado, o instrumento apresentou-se adequado estatisticamente. As medianas dos 159 estudantes analisados apresentam-se deslocadas no sentido mais autorregulado do continuum com destaque para a regulação identificada, o que evidencia que a motivação dos discentes deve-se ao reconhecimento da importância da profissão docente. Além disso, por meio dos cálculos de correlação, foi possivel perceber que os fatores além de poderem se apresentar de forma concomitante podem fortalecer os constructos em uma direção do continuum enquanto contribuem negativamente para os fatores do sentido oposto. Dessa forma, concluímos que é preciso atenção, emocionalmente responsável, a fim de fomentar a percepção de importância da profissão, pois há forte evidência de que ela seja capaz de contribuir com o desenvolvimento da motivação intrínseca para ser Professor.

Palavras-chave: Autodeterminação. Licenciatura. Quantitativa.

\section{COLLEGE DEGREE: choice or lack of options}

\begin{abstract}
At first, no one disagrees that education is essential to the country's progress. However, this concern does not translate into appreciation of the teaching profession, whether it is in terms of working conditions or salary. Despite all the problems, there are still students who enter undergraduate courses, remain and become teachers throughout the country in various educational institutions. Thus, the

1 Doutora em Química (UFSCar). Professora do Programa de pós-graduação em ensino de ciências - Universidade de Brasília. ORCID iD: https://orcid.org/0000-0003-4266-4377. E-mail: jeniffer.toledo@gmail.com

2 Licenciando em Química - Universidade de Brasília. ORCID iD: https://orcid.org/0000-00025340-9948. E-mail: henricoten@gmail.com
\end{abstract}

Revista Exitus, Santarém/PA, Vol. 10, p. 01-30, e020029, 2020. 
purpose of this article was to analyze what motivates students to stay in a degree course in Chemistry at UnB. To answer the research question, the quantitative methodology was used, and a questionnaire based on the Likert type selfdetermination theory questionnaire was developed. As a result, the instrument was statistically adequate. The medians of the 159 students analyzed are displaced in the most self-regulating sense of the continuum with emphasis on the identified regulation, which shows that the motivation of the students is due to the recognition of the importance of the teaching profession.Moreover, through the correlation calculations it was possible to realize that factors besides being present concomitantly can strengthen the constructs in one direction of the continuum while contributing negatively to the factors in the opposite direction. Thus, we conclude that emotionally responsible attention in needed to foster the perception of the importance of the profession, as there is strong evidence that it is able to contribute to the development of intrinsic motivation to be a teacher.

Keywords: Self-determination. Degree. Quantitative.

\section{GRADO UNIVERSITARIO: elección o falta de opción}

\section{RESUMEN}

Al principio, nadie está en desacuerdo con que la educación es esencial para el progreso del país. Sin embargo, esta preocupación no se traduce en una apreciación de la profesión docente, ya sea en términos de condiciones de trabajo o sueldo. A pesar de todos los problemas, todavía hay estudiantes que ingresan a carreras, permanecen y se convierten en maestros en todo el país, en diversas instituciones educativas. Por lo tanto, el propósito de este artículo es analizar qué motiva a los estudiantes a permanecer en uma carrera grado em Química en la UnB. Para responder a la pregunta de investigación, se utilizó la metodología cuantitativa y se desarrolló un cuestionario basado en la teoría de autodeterminación de Likert. Como resultado, el instrumento fue estadísticamente adecuado. Las medianas de los 159 estudiantes analizados están desplazadas en el sentido más autorregulador del continuo con énfasis en la regulación identificada, lo que demuestra que la motivación de los estudiantes se debe al reconocimiento de la importancia de la profesión docente. Además, a través de los cálculos de correlación, fue posible darse cuenta de que los factores además de estar presentes concomitantemente pueden fortalecer los constructos en una dirección del continuo mientras contribuyen negativamente a los factores em la dirección opuesta. Por lo tanto, concluímos que se necesita una atención emocionalmente responsable para fomentar la percepción de la importancia de la profesión, ya que hay pruebas contundentes de que puede contribuir al desarrollo de la motivación intrínseca para ser maestro.

Palabras clave: Autodeterminación. Grado. Cuantitativo.

\section{INTRODUÇÃO}

O período da Contrarreforma, visando expandir pelo mundo a fé católica, trouxe ao Brasil os jesuítas. Assim, iniciou-se um processo educativo 
com um forte caráter doutrinário que perdurou até serem expulsos pelo Marquês de Pombal sob acusação de estarem conspirando contra o Estado. A partir desse momento, a Educação no Brasil passa a ser responsabilidade estatal e, sem investimentos, fica praticamente abandonada (NOSELLA, 2005).

Em termos de política pública, o governo passa a controlar o direito ao exercício da docência exigindo a aprovação em um exame referente ao conteúdo a ser lecionado. Escolas Normais são criadas com o objetivo de preparar para o exercício do magistério sendo nelas ministrados, basicamente, o conteúdo específico e uma disciplina pedagógica (BERNARDO, 1989).

Durante o governo de Getúlio Vargas, a desigualdade social e a cobrança popular culminaram na ampliação da oferta de escolas, o que gerou uma maior necessidade por docentes. Assim, a fim de suprir a demanda, foram criados vários cursos para a formação dos professores sem, contudo, a preocupação com a qualidade. As condições de trabalho, que já não eram satisfatórias, tornaram-se ainda mais precárias. A desvalorização da docência também era reforçada pelos licenciandos, os quais viam as disciplinas pedagógicas como uma perfumaria, considerando-as irrelevantes (BERNARDO, 1989).

A licenciatura como uma política pública passou por diversas reformas até a configuração atual. No modelo inicial, inspirado no sistema francês $[3+1]$, o estudante tinha 3 anos de formação na área do conhecimento específico e um ano de disciplinas pedagógicas que deveriam instrumentalizá-lo (FERREIRA, KASSEBOEHMER, 2012). Era notória a incapacidade de abarcar as questões que envolvem o processo de ensinoaprendizagem em 1 ano de curso. Assim, com a ampliação da demanda social por qualidade e não apenas acesso, esse paradigma foi se tornando insustentável.

Em 2002, foi publicada a resolução do Conselho Nacional de Educação /Conselho Pleno Resolução (CNE/CP) no 2, a qual, entre várias outras questões, instituiu que entre as $2800 \mathrm{~h}$ totais do curso, 400 horas 
deveriam ser destinadas à prática como componente curricular distribuídas ao longo do currículo, além das $400 \mathrm{~h}$ de estágio curricular supervisionado a partir da metade do curso (BRASIL, 2002). Embora essa resolução tenha sido um marco importante na formação de professores, foi substituída em 2015 (BRASIL, 2015) por outra que, ainda no ano de 2019, está em vias de implementação por algumas Instituições de Ensino.

A resolução de julho de 2015 amplia a carga horária total para 3200h, porém a prática como componente curricular permanece inalterada. As 400h de estágio agora não estão restritas à segunda metade do curso, o que permite ao estudante vivenciar a sala de aula mais cedo. Além disso, no Artigo 11, indica-se a necessidade de um projeto de formação com identidade própria, reforçando a ideia de que o curso de Licenciatura não visa formar bacharéis e, portanto, deve ser fundamentalmente diferente do bacharelado (GATTI, BARRETO, ANDRÉ, 2011; GATTI, 2014).

Embora os estudiosos em educação não duvidem da importância e da identidade ímpar de um curso de Licenciatura, essa concepção não é unânime e bem aceita pela sociedade e demais profissionais. Podemos citar como exemplo, a fim de referendar esse argumento, o embate ocorrido entre o Conselho Estadual de Educação do Estado de São Paulo (CEE) e as Universidades Paulistas.

Em 15 de março de 2012, foi publicada no Diário Oficial (BRASIL, 2012) a deliberação do CEE no. 111 cujo Artigo 8 instituiu que os cursos de formação de professores deveriam destinar, no mínimo, 30\% da carga horária total para a formação didático-pedagógica. O estágio supervisionado não faz parte desse cômputo.

A deliberação veio a fim de sanar o fato de que muitos cursos não destinavam $10 \%$ da carga horária a essas questões, pois de forma geral, a preocupação vinha sendo na formação de, por exemplo, químicos e não professores de química, conforme afirmou a conselheira Rose Neubaver em entrevista à Folha. Embora o CEE seja um órgão superior às universidades, a deliberação não foi recebida com tranquilidade. A Universidade de São Paulo (USP), a Universidade Estadual Paulista (Unesp) e a Universidade de 
Campinas (Unicamp) contestaram a regra solicitando sua revogação, além de ameaçarem entrar na justiça. Porém, mesmo diante da pressão, a deliberação não foi revogada e o CEE afirmou que a recusa em cumprir geraria a não renovação da licença para o funcionamento dos cursos, o que impediria a emissão de diplomas (TAKAHASHI, 2015).

Questionado sobre o porquê da negativa, o coordenador do curso de Licenciatura em Química do campus central da USP afirmou que a adaptação do currículo custou a redução da carga horária de disciplinas de Química. Com esse novo currículo, os alunos que entravam na Licenciatura visando trabalhar na indústria seriam prejudicados e consequentemente evadiriam (TAKAHASHI, 2015).

Essa visão, lamentável, do coordenador do curso, que coloca a Licenciatura como um subcurso cuja função principal seria servir de porta de acesso a outras profissões, é compartilhada por parte do público da reportagem conforme pode ser visualizado na Figura 1.

FIGURA 1 - Caixa de comentários da reportagem

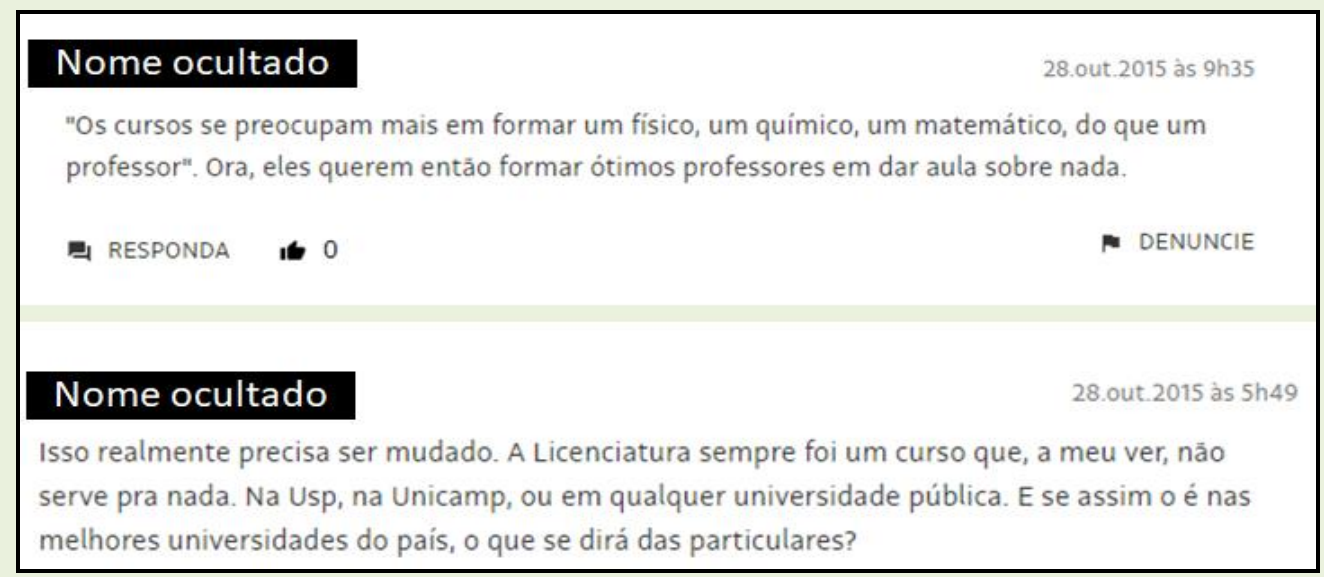

Fonte: Takahashi, 2015.

Podemos perceber, em ambos os comentários, a visão de que as matérias específicas, como Química, Física e Matemática, devem preencher o currículo ou os professores formados nesses cursos não serão capazes de lecionar, pois o tempo que poderia estar sendo dedicado a essas disciplinas estava sendo utilizado com assuntos, por eles, considerados menos importantes. 
A desvalorização do curso de Licenciatura também pode ser exemplificada quando na manchete do jornal Metro lemos que "professor e garçom estão entre os bicos mais buscados" (ROSA, 2016), conforme pode ser visualizado na Figura 2, ou quando em propagandas de formação pedagógica a Anhanguera e a Unopar (Figura 3), universidades que fazem parte do grupo Kroton, afirmam "Torne-se professor e aumente sua renda" (HUCK, 2017).

FIGURA 2 - Capa do Jornal Metro

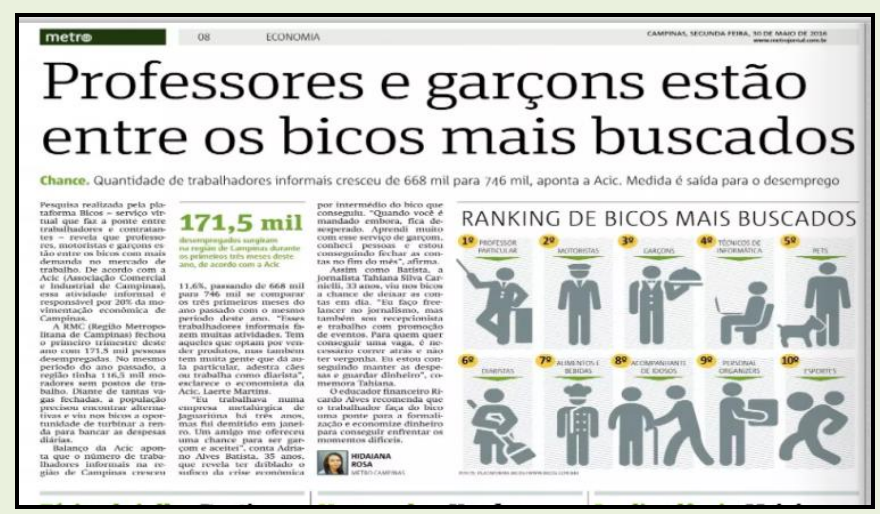

Fonte: Rosa, 2016.

FIGURA 3 - Peças publicitárias de Universidades do grupo Kroton
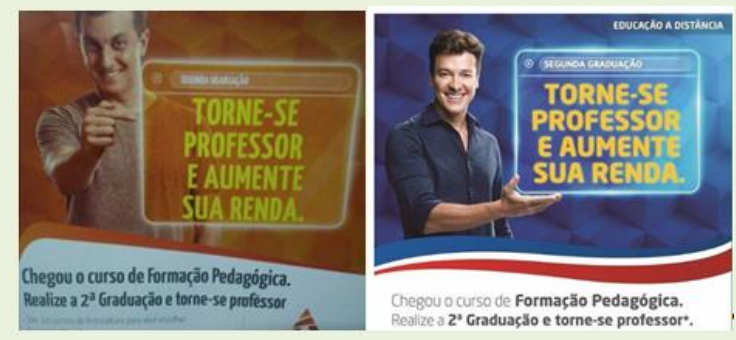

Fonte: Huck, 2017.

Essa desvalorização da profissão docente não está apenas estampada nas manchetes, comentários, peças publicitárias, crença de que as disciplinas pedagógicas são perfumaria, mas está também carimbada nos abjetos salários por todo o País. No ano de 2018, o piso salarial estipulado pelo MEC (Ministério da Educação) era de $R \$ 2.455,35$ para $40 \mathrm{~h}$ semanais sendo que, segundo levantamento realizado pela Gazeta do Povo por meio de informações enviadas por sindicatos e Secretarias de Educação, Fazenda e Administração, nem todos os estados cumprem o mínimo. A média salarial 
apresentada pela reportagem pode ser visualizada na Figura 4 (SANTIAGO, 2019).

FIGURA 4-Média salarial dos professores no ano de 2018 em R\$

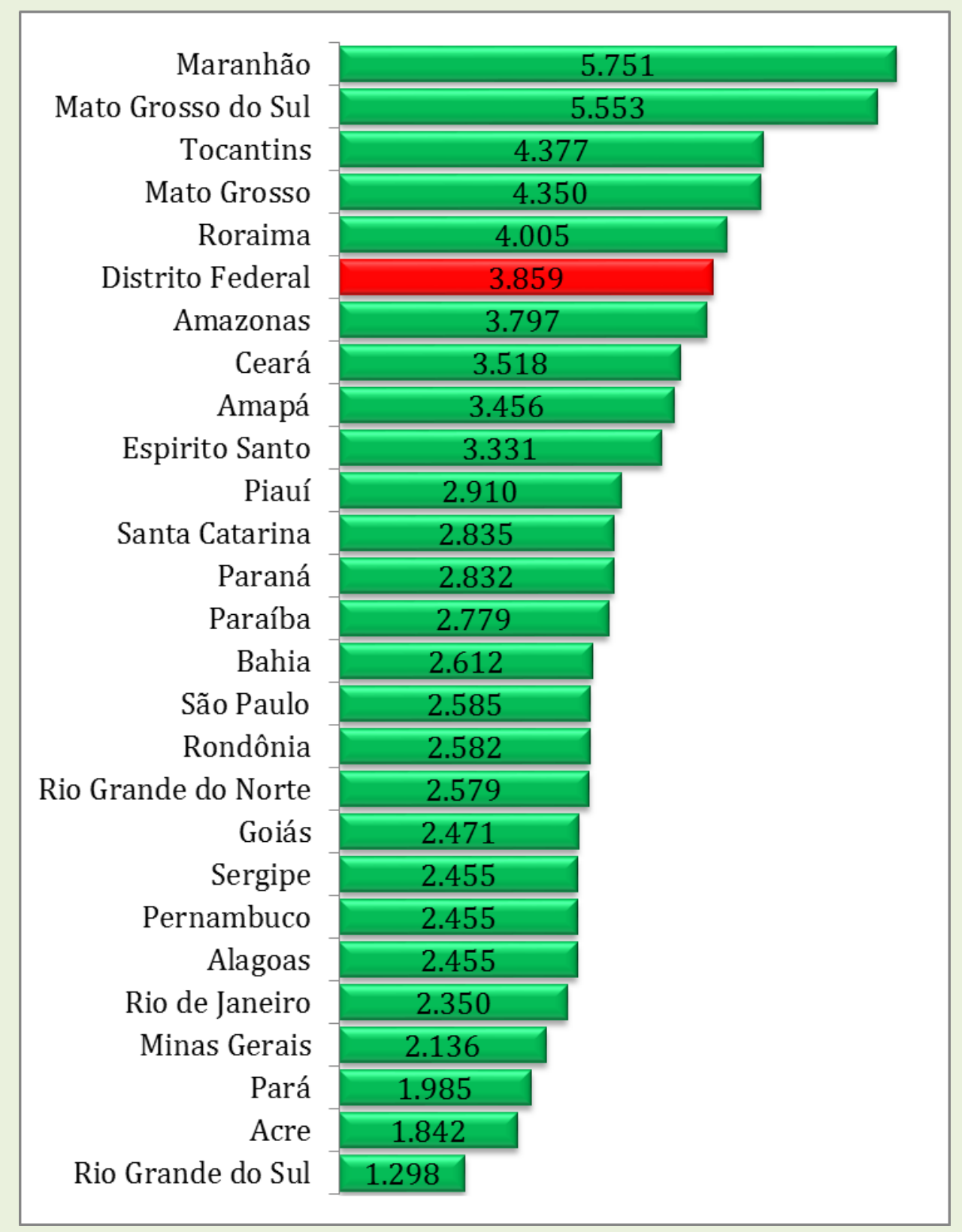

Fonte: Adaptado de Santiago, 2019.

Chamamos a atenção para o título da reportagem "Mesmo em crise, estados pagam acima do piso para professores, veja ranking" (SANTIAGO, 2019). Embora não haja nada de falacioso no título, o piso estipulado pelo MEC para aquele ano (2018) representava menos da metade do salário recebido por outros profissionais com a mesma titulação. Dados da Pesquisa 
Nacional por Amostra de Domicílios, realizada pelo Instituto Brasileiro de Geografia e Estatística (IBGE), publicados em reportagem de o Globo (ALMEIDA, 2018), apontam que profissionais com nível superior ganham, em média, $R \$ 5.110$ enquanto os com nível médio apenas $R \$ 1.727$. Dessa forma, podemos perceber que o salário do professor mais se aproxima daqueles com nível médio do que os de igual titulação. Esse dado, de acordo com a Organização para a Cooperação e Desenvolvimento Econômico (OCDE), expõe a grande desigualdade social que assola o país (IBGE, 2018) e o baixo valor atribuído aos docentes que têm sua dignidade colocada em xeque.

A decadência dos salários está diretamente relacionada à diminuição da dignidade atribuída a uma categoria profissional, sendo um aspecto decisivo e revelador de um processo de declínio no valor social da profissão docente (SOUTO, 2016, p.1085).

O baixo status social e as más condições de trabalho, segundo Souto (2016) têm favorecido o abandono da profissão docente, o que de acordo com a autora correspondeu a $53 \%$ dos formados no curso de Licenciatura em Matemática na Universidade Federal de São João Del-Rei até julho de 2012. Além disso, dados do Censo da Educação Superior de 2018 apontaram que apenas $20,5 \%$ dos estudantes matriculados no ensino superior escolheram a Licenciatura, sendo estes, em sua maioria, pela primeira vez na história brasileira, em cursos a distância (INEP, 2019).

Através dos dados do Censo da Educação Superior de 2018 (INEP, 2019) e do Censo Populacional divulgado pelo IBGE com data de referência em $1^{\circ}$ de julho de 2018 (BRASIL, 2018), foi possível calcular o número de estudantes a concluir o curso de Licenciatura em Química no ano de 2018 por milhão de habitantes em sua respectiva Unidade Federativa. Além disso, foi mensurada a porcentagem de evasão através da soma entre matrículas trancadas, matrículas desvinculadas, alunos transferidos e alunos falecidos. Os valores totais podem ser visualizados no Quadro 1.

Os números obtidos não são nada animadores, principalmente quando focamos no Distrito Federal, unidade onde se encontra nosso público alvo. A capital do país, embora compute um dos melhores salários 
para professor, apresentou um baixo número de licenciandos em Química formados por milhão de habitantes. Além disso, a evasão ficou em $50 \%$ no ano de 2018 e se analisarmos apenas a Universidade de Brasília, esse número sobe para $62 \%$ de acordo com os dados oficiais divulgados à comunidade interna pelo Decanato de Planejamento, Orçamento e Avaliação Institucional.

QUADRO 1 - Número de estudantes a concluírem o curso de licenciatura em química por milhão de habitantes e porcentagem de evasão

\begin{tabular}{|c|c|c|c|c|c|}
\hline Estados & $\begin{array}{c}\text { Concluintes } \\
\text { por milhão } \\
\text { de } \\
\text { habitantes }\end{array}$ & $\begin{array}{c}\% \\
\text { Evasão }\end{array}$ & Estados & $\begin{array}{c}\text { Concluinte } \\
\text { s por } \\
\text { milhão de } \\
\text { habitantes }\end{array}$ & $\begin{array}{c}\% \\
\text { Evasão }\end{array}$ \\
\hline Rondônia & 29 & 41 & Sergipe & 24 & 37 \\
\hline Acre & 38 & 55 & Bahia & 11 & 34 \\
\hline Amazonas & 27 & 22 & Minas Gerais & 24 & 42 \\
\hline Roraima & 45 & 63 & Espírito Santo & 19 & 27 \\
\hline Pará & 10 & 57 & Rio de Janeiro & 13 & 68 \\
\hline Amapá & 68 & 28 & São Paulo & 18 & 45 \\
\hline Tocantins & 19 & 13 & Paraná & 25 & 42 \\
\hline Maranhão & 19 & 21 & Santa Catarina & 8 & 54 \\
\hline Piauí & 62 & 26 & Rio Grande do Sul & 13 & 57 \\
\hline Ceará & 21 & 54 & Mato Grosso do Sul & 26 & 38 \\
\hline $\begin{array}{c}\text { Rio Grande } \\
\text { do Norte }\end{array}$ & 27 & 46 & Mato Grosso & 22 & 78 \\
\hline Paraíba & 28 & 31 & Goiás & 28 & 40 \\
\hline Pernambuco & 21 & 31 & Distrito Federal & 17 & 50 \\
\hline Alagoas & 35 & 45 & & & \\
\hline
\end{tabular}

Fonte: Brasil, 2019; Brasil, 2018.

Tais dados, embora preocupantes, são melhores do que os obtidos por Cunha, Tunes e Silva (2001). Os autores detectaram um alarmante valor de 86\% ocasionado, principalmente, pelas sucessivas reprovações em disciplinas, o que nos leva a concordar com Freire (1997) ao afirmar que os alunos não evadem, mas são evadidos.

O prejuízo com a saída do aluno do curso é certo: perde o aluno ao não se diplomar, perde o professor que não se realiza como educador, a universidade, a família e a sociedade. Perde também o País, que olha para o futuro e espera... (CUNHA, TUNES, SILVA, 2001, p.279). 
Assim, diante do baixo status social e remuneratório da profissão docente, da tentativa de desmonte da educação pública de qualidade não podemos nos calar. É preciso ir além do resistir, precisamos lutar e lutando ensinamos para além da sala de aula o exercício da cidadania.

\begin{abstract}
A minha resposta à ofensa à educação é a luta política consciente, crítica e organizada contra os ofensores [...]. Uma das formas de luta contra o desrespeito dos poderes públicos pela educação, de um lado, é a nossa recusa a transformar nossa atividade docente em puro bico, e de outro, a nossa rejeição a entendê-la e a exercê-la como prática afetiva de "tias e de tios" (FREIRE, 1996, p.40).

Quanto mais aceitamos ser tias e tios, tanto mais a sociedade estranha que façamos greve e exige que sejamos bem comportados (FREIRE, 1997, p. 33).
\end{abstract}

Diante do contexto aqui exposto, acreditamos que a alarmante evasão deve nos provocar para além do diagnóstico, ela deve ser força para a luta preconizada por Freire (1996). Dessa forma, optamos, nesta pesquisa, por olhar para evasão sob os olhos não dos que são evadidos, mas daqueles que ficam, pois entendemos que ao analisarmos os que resistem, poderemos pensar sobre estratégias para a redução de evasão, além de construirmos um ambiente melhor para nossos discentes. Portanto, neste trabalho pretendemos validar um questionário a fim de entender o que motiva estudantes de um curso de Licenciatura em Química a serem professores. Para a construção do questionário, do tipo likert, utilizamos a Teoria da Autodeterminação de Deci e Ryan (1985).

\title{
Teoria da Autodeterminação
}

Motivação, que vem do verbo latino movere, cujo tempo supino motum e o substantivo motivum, do latim tardio, deram origem ao nosso termo semanticamente aproximado, que é motivo. Assim, genericamente, a motivação, ou o motivo, é aquilo que move uma pessoa ou a põe em ação ou faz mudar o curso (BORUCHOVITCH, BZUNECK, 2009, p.9).

A motivação pode ser classificada segundo seu lócus de origem como intrínseca, quando é proveniente de motivos internos, e extrínseca quando 
os fatores determinantes são externos (REEVE, 2006). Opostamente à motivação intrínseca, temos a desmotivação que, embora seja um conceito descritivo, refere-se ao fato do sujeito não investir qualquer esforço para fazer uma tarefa (BORUCHOVITCH, BZUNECK, 2009).

A motivação intrínseca gera um comportamento motivado pela própria ação, ou seja, o indivíduo faz suas escolhas baseado no prazer que elas the proporcionam. Assim, o movimento é um fim em si mesmo, sendo a execução a própria recompensa. Como uma característica desse estado, temos indivíduos altamente concentrados na atividade a ponto de perderem a noção do tempo. Indivíduos que mesmo diante de emoções negativas não têm seu desempenho prejudicado. Quando motivado intrinsecamente, o sujeito não se preocupa com o reconhecimento dos demais na realização da tarefa, pois a opinião externa não o influencia. Além disso, erros são vistos como desafios que o impelem a continuar persistindo (BORUCHOVITCH, BZUNECK, 2009).

A motivação extrínseca não está fundamentada no prazer, mas em mecanismos punitivos e compensatórios. O indivíduo comporta-se não porque sente satisfação, mas para evitar sentimentos negativos por causa de punições ou para promover sentimentos positivos oriundos das recompensas (BORUCHOVITCH, BZUNECK, 2009).

Embora a classificação intrínseca e extrínseca possibilite várias inferências, ela foi considerada simplista por Deci e Ryan (1985) que estabeleceram uma subdivisão dos fatores externos de forma a gerar um continuum motivacional. Devemos ressaltar que o locus de causalidade não é engessado na vida de um indivíduo, podendo se situar em diferentes pontos para distintos momentos e aspectos da vida (BORUCHOVITCH, BZUNECK, 2009). O continuUm motivacional extrínseco se divide nos seguintes fatores:

Regulação Externa: demanda a presença de um agente punidor e/ou recompensador. Nesse caso, o sujeito age para não ser punido ou para ser recompensado diretamente por alguém (BORUCHOVITCH, BZUNECK, 2009). 
Regulação Introjetada: a presença de um agente para punir ou recompensar se faz desnecessária, pois o sujeito já introjetou que precisa se comportar de uma determinada forma pois, caso não o faça, sua consciência irá cobrá-lo (BORUCHOVITCH, BZUNECK, 2009). Dessa maneira, a pressão é interna, mas motivada por fatores extrínsecos.

Regulação Identificada: refere-se à percepção de importância pessoal da atividade, assim o indivíduo irá agir não por receio de ser punido ou por desejo de ser recompensando. A consciência também não é fator impedidor, mas sim o reconhecimento da ação como relevante para suas necessidades pessoais (BORUCHOVITCH, BZUNECK, GUIMARÃES, 2010).

Regulação Integrada: o comportamento direciona-se no sentido de colocar o sujeito em contato com o seu verdadeiro self, portanto a decisão é tomada de forma a conectá-lo com o sentido pessoal de vida. Nesse caso, as demandas externas servem como fontes de informação a fim de ajustar a ação.

Uma representação esquemática do continuum motivacional pode ser visualizada na Figura 5.

FIGURA 5 - Representação esquemática do continuum de autodeterminação

\begin{tabular}{|c|c|c|c|c|c|}
\hline \multirow{2}{*}{ Desmotivação } & \multicolumn{4}{|c|}{ Motivação Extrínseca } & \multirow{2}{*}{$\begin{array}{l}\text { Motivação } \\
\text { Intrinseca }\end{array}$} \\
\hline & $\begin{array}{c}\text { Regulação } \\
\text { Externa }\end{array}$ & $\begin{array}{l}\text { Regulação } \\
\text { Introjetada }\end{array}$ & $\begin{array}{l}\text { Regulação } \\
\text { Identificada }\end{array}$ & $\begin{array}{l}\text { Regulação } \\
\text { Integrada }\end{array}$ & \\
\hline
\end{tabular}

Fonte: os autores.

A regulação motivacional, segundo Deci e Ryan (1985), é feita por meio da força de vontade e pode resultar em um comportamento mais motivado ou desmotivado a depender de como as informações ambientais são percebidas e julgadas pelo indivíduo.

Dessa forma, entender onde está a regulação motivacional do estudante, predominantemente, pode nos auxiliar na busca por alternativas a fim de conduzi-lo para o nível mais autorregulado, a motivação intrínseca. No nosso caso, isso significa auxiliar nossos estudantes a sentirem prazer com 
a profissão docente. Assim, foi dentro desse escopo que essa pesquisa se inseriu.

Este trabalho teve como objetivo responder à seguinte questão de pesquisa: Qual a motivação dos estudantes do curso de Licenciatura em Química da Universidade de Brasília para serem docentes?

\section{Metodologia}

Esta pesquisa é do tipo quantitativa, portanto faz uso da psicometria para mensurar as informações que serão analisadas no estudo (GUIMARÃES, 2003; TOLEDO, 2015).

A fim de responder à questão de pesquisa, foi construído um questionário do tipo Likert de 5 pontos. $O$ instrumento contém 30 afirmativas sendo 5 para cada um dos constructos. Essas afirmações foram misturadas de forma a resultar em uma ferramenta com fatores aleatórios a fim de minimizar respostas enviesadas, como preconiza a psicometria. Esse questionário foi submetido à análise de 3 juízes para validar os fatores: 1 especialista na teoria da autodeterminação e produção de questionários, 1 especialista na teoria da autodeterminação e em cursos de Licenciatura em Química e 1 especialista em cursos de Licenciatura em Química. Após a adequação, o instrumento foi aplicado na sua forma piloto em 200 estudantes de diversos cursos de Licenciatura da região de interesse. Com os resultados obtidos, o instrumento foi readequado gerando sua estrutura final que pode ser visualizada no Quadro 2.

Para cada um dos itens, o respondente deveria, por meio de uma escala Likert de 5 pontos, indicar o quanto concordavam com cada assertiva, sendo 1 discordo totalmente e 5 concordo totalmente.

O instrumento foi aplicado em 159 estudantes do curso de Licenciatura em Química da Universidade de Brasília. A amostra é por conveniência, pois os questionários foram aplicados a partir da concordância em ceder tempo de aula por diferentes professores. Cada aplicação durou aproximadamente 30 minutos. 
QUADRO 2: Afirmativas para mensurar a motivação em ser professor segundo a teoria da autodeterminação

\begin{tabular}{|c|c|}
\hline$n^{\circ}$ & Afirmativas \\
\hline 1 & Eu já tive razões para cursar licenciatura; agora, porém, me pergunto se devo continuar. \\
\hline 2 & Eu curso licenciatura porque eu preciso. \\
\hline 3 & Eu continuo na licenciatura porque eu me sentiria mal se não terminasse. \\
\hline 4 & Eu curso licenciatura porque é um bom modo de desenvolver atributos pessoais que valorizo. \\
\hline 5 & Eu curso licenciatura porque ser professor reflete quem eu sou. \\
\hline 6 & Eu curso licenciatura pelo prazer que tenho quando converso sobre a docência. \\
\hline 7 & Acho que estou perdendo tempo no curso de licenciatura, não tenho motivos para prosseguir. \\
\hline 8 & Eu curso licenciatura porque sou pressionado a continuar. \\
\hline 9 & $\begin{array}{l}\text { Eu continuo na licenciatura porque quero provar para as pessoas que sou capaz de completar } \\
\text { o curso. }\end{array}$ \\
\hline 10 & Eu curso licenciatura porque eu considero que professor é uma profissão importante. \\
\hline 11 & Eu curso licenciatura porque eu sinto que nasci para ser professor. \\
\hline 12 & $\begin{array}{l}\text { Eu curso licenciatura pela satisfação que sinto quando estou realizando atividades específicas } \\
\text { da Licenciatura. }\end{array}$ \\
\hline 13 & Eu curso licenciatura porque sofro uma pressão externa para prosseguir. \\
\hline 14 & Eu curso licenciatura porque eu sinto que ser professor é parte da minha missão de vida. \\
\hline 15 & Eu continuo na licenciatura para provar a mim mesmo que sou capaz de completar o curso. \\
\hline 16 & Eu penso em desistir da Licenciatura. \\
\hline 17 & Eu curso licenciatura porque a escolhi como um modo de crescimento pessoal. \\
\hline 18 & Eu curso licenciatura porque eu me sinto feliz em poder ser professor. \\
\hline 19 & Eu curso licenciatura porque eu passei no exame e minha família me obriga a continuar. \\
\hline 20 & Eu curso licenciatura, mas preferia estar em outro curso. \\
\hline 21 & $\begin{array}{l}\text { Eu curso licenciatura porque acredito que posso ser útil na vida de muitas pessoas por meio da } \\
\text { docência e isso é relevante para mim. }\end{array}$ \\
\hline 22 & Eu curso licenciatura porque sinto prazer quando leio assuntos relacionados à docência. \\
\hline 23 & Eu curso licenciatura porque ser professor faz com que eu me sinta realizado. \\
\hline 24 & Eu continuo na licenciatura porque não quero que as pessoas me vejam como um fracassado. \\
\hline 25 & Eu continuo na licenciatura, mas estou infeliz no curso. \\
\hline 26 & Eu curso licenciatura porque pessoas me pressionam a continuar. \\
\hline 27 & Eu curso licenciatura porque ensinar é um prazer. \\
\hline 28 & Eu continuo na licenciatura porque me sentiria inútil na sociedade se não completasse o curso. \\
\hline 29 & $\begin{array}{l}\text { Eu curso licenciatura porque acredito que posso contribuir com a melhora da Educação no } \\
\text { Brasil e isso é importante para mim. }\end{array}$ \\
\hline 30 & Eu curso licenciatura porque ser professor se adéqua aos meus interesses e valores. \\
\hline
\end{tabular}

Fonte: os autores.

Revista Exitus, Santarém/PA, Vol. 10, p. 01-30, e020029, 2020. 
Os sujeitos de pesquisa são pertencentes a um curso de Licenciatura em Química no qual, atualmente, encontram-se matriculados 259 discentes. O curso é noturno e constituído por 232 alunos com até 24 anos, sendo 93 brancos, 7 amarelos, 78 pardos, 23 pretos e 58 que não disponibilizaram tal informação. Em relação à entrada no ensino superior por cota, apenas 85 fizeram uso, sendo:

-25 Escola Pública Alta Renda não preto pardo indígena,

-25 Escola Pública Alta Renda preto pardo indígena,

-6 Escola Pública Baixa Renda não preto pardo indígena,

-17 Escola Pública Baixa Renda preto pardo indígena,

-12 Negro.

Para verificar a adequabilidade da população analisada, foram realizados o teste Kaiser-Meyer-Olkin (KMO) e o teste de esfericidade de Bartlett. A fim de confirmar a validade corroborada pelos juízes, foi realizada uma análise fatorial exploratória com componentes principais e rotação do tipo varimax. Ademais, cada constructo foi submetido ao cálculo do alfa de Cronbach para verificação da consistência interna dos itens.

Além disso, os dados foram submetidos a análise de normalidade com o teste de Kolmogorov-Smirnov, as medianas foram comparadas pelo teste de Wilcoxon e as correlações aferidas pelo coeficiente de Spearman.

\section{Resultados e Discussão}

Todos os dados apresentados foram calculados para uma confiança de $95 \%$. Para analisar a adequabilidade da amostra foi calculado o KMO e esfericidade de Bartlett tendo como resultado 0,87 e $p=0,000$, respectivamente. A amostra, portanto, demonstra-se adequada para a realização da análise fatorial.

O instrumento foi submetido à análise fatorial exploratória pelo método de componentes principais e rotação varimax resultando em 6 fatores com valor próprio (eigenvalue) maior que 1. Algumas questões foram removidas por não se enquadrarem, estatisticamente, à hipótese inicial. A matriz final 
com os devidos pesos fatoriais das questões que foram mantidas pode ser visualizada na Tabela 1.

TABELA 1 - Matriz de componente rotativa varimax

\begin{tabular}{|c|c|c|c|c|c|c|}
\hline $\begin{array}{l}\text { Questã } \\
\quad 0\end{array}$ & $\begin{array}{c}\text { Regulaçã } \\
\circ \\
\text { Integrada }\end{array}$ & $\begin{array}{c}\text { Regulaçã } \\
0 \\
\text { Externa }\end{array}$ & $\begin{array}{l}\text { Motivação } \\
\text { Intrínseca }\end{array}$ & $\begin{array}{c}\text { Desmotivaçã } \\
0\end{array}$ & $\begin{array}{c}\text { Regulaçã } \\
\circ \\
\text { Introjetad } \\
a\end{array}$ & $\begin{array}{l}\text { Regulação } \\
\text { Identificada }\end{array}$ \\
\hline 14 & 0,78 & & & & & \\
\hline 5 & 0,76 & & & & & \\
\hline 11 & 0,75 & & & & & \\
\hline 30 & 0,69 & & & & & \\
\hline 26 & & 0,83 & & & & \\
\hline 19 & & 0,83 & & & & \\
\hline 13 & & 0,70 & & & & \\
\hline 2 & & 0,60 & & & & \\
\hline 22 & & & 0,77 & & & \\
\hline 6 & & & 0,75 & & & \\
\hline 12 & 0,50 & & 0,69 & & & \\
\hline 16 & & & & 0,78 & & \\
\hline 1 & & & & 0,72 & & \\
\hline 25 & & & & 0,68 & & \\
\hline 3 & & & & & 0,81 & \\
\hline 15 & & & & & 0,66 & \\
\hline 28 & & & & & 0,66 & \\
\hline 4 & & & & & & 0,72 \\
\hline 17 & & & & & & 0,70 \\
\hline 10 & 0,49 & & & & & 0,56 \\
\hline
\end{tabular}

Fonte: os autores.

Cada linha da matriz corresponde a uma variável observável, ou seja, uma afirmação presente no questionário. Cada coluna corresponde a uma variável não observável, ou seja, um fator ou, também denominado, constructo. Os valores que aparecem nessa matriz referem-se a quanto cada variável observável contribui com a não observável. Na primeira linha, por exemplo, a questão 14 tem peso de 0,78 na regulação integrada e não contribui significativamente com nenhum dos outros constructos.

Esses resultados, somados à avaliação dos juízes, nos permitem afirmar que o questionário, possivelmente, mede aquilo que ele se propõe a medir: Desmotivação, Regulação Externa, Regulação Introjetada, Regulação Identificada, Regulação Integrada e Motivação Intrínseca. 
As questões foram ordenadas segundo o peso de suas cargas fatoriais (Tabela 1), sendo que os valores inferiores a 0,4 foram suprimidos conforme recomendado por Hair et al (2006) citado por Ariani (2013).

Segundo Guimarães (2003), as cargas fatoriais maiores do que 0,6 são consideradas altas, cargas moderadas situam-se entre 0,3 e 0,6 e cargas inferiores a 0,3 devem ser desconsideradas. Assim, podemos perceber que todos os fatores são compostos basicamente por cargas altas, exceto a regulação identificada que contém uma questão com carga moderada.

A precisão de cada fator foi mensurada pelo Alfa de Cronbach que varia entre 0 e 1 (ARAUJO, 2009), sendo sua classificação determinada por Freitas e Rodrigues (2005) conforme pode ser visualizado no Quadro 3.

QUADRO 3 - Classificação qualitativa do Alfa de Cronbach

\begin{tabular}{|c|c|c|c|c|}
\hline Muito baixo & Baixo & Moderado & Alto & Muito Alto \\
\hline$a \leq 0,3$ & $0,3<a \leq 0,6$ & $0,6<a \leq 0,75$ & $0,75<a \leq 0,90$ & $a>0,90$ \\
\hline
\end{tabular}

Fonte: Freitas e Rodrigues (2005).

Os valores do alfa de Cronbach obtidos para nossos constructos podem ser visualizados na Tabela 2.

TABELA 2 - Alfa de Cronbach para os constructos

\begin{tabular}{c|c|c} 
Constructo & Questões & $\begin{array}{c}\text { Alfa de } \\
\text { Cronbach }\end{array}$ \\
\hline Regulação Integrada & $14,5,11,30$ & 0,86 \\
\hline Regulação Externa: & $26,19,13,2$ & 0,83 \\
\hline Motivação Intrínseca: & $22,6,12$ & 0,85 \\
\hline Desmotivação: & $16,1,25$ & 0,74 \\
\hline Regulação Introjetada: & $3,15,28$ & 0,67 \\
\hline Regulação Identificada: & $4,17,10$ & 0,61
\end{tabular}

Fonte: os autores.

Dessa maneira, podemos perceber que a consistência interna de cada um dos constructos se situa em um nível adequado (moderado a alto) para inferências qualitativas acerca da população estudada. Portanto, podemos afirmar, estatisticamente, que o instrumento utilizado é pertinente para permitir exploração qualitativa dos motivos que levam os estudantes do curso de Licenciatura em Química a continuarem o referido curso. 
Para averiguar essas razões, os dados da população estudada foram dispostos em termos de mediana conforme pode ser verificado na Tabela 3. A escolha da mediana em detrimento da média, como usado popularmente, tem respaldo teórico em razão de os valores apresentados não fazerem parte de uma mensuração contínua, mas de uma escala. Ademais, médias são "maquiadas" por outliers (TOLEDO, 2015).

TABELA 3 - Mediana dos constructos estudados

\begin{tabular}{c|c}
\hline Constructo & Mediana \\
\hline Desmotivação: & 1,75 \\
\hline Externa: & 1,25 \\
\hline Introjetada: & 1,80 \\
\hline Identificada: & 4,33 \\
\hline Integrada & 3,60 \\
\hline Intrínseca: & 4,00 \\
\hline
\end{tabular}

Fonte: os autores.

Os dados obtidos nos levam a perceber que a razão dos nossos alunos estarem cursando Licenciatura em Química é autorregulada, ou seja, mais deslocado no sentido de fatores próximos ao intrínseco do que da desmotivação. Porém, antes de fazermos explanações acerca dos valores obtidos, é preciso verificar se os motivos menos autorregulados são de fato, significativamente, diferentes dos autorregulados, ou se essa variação se encontra dentro da faixa de erro estatística.

A fim de validar essa diferença estatística foi verificada a normalidade de cada um dos constructos considerando-se suas respectivas medianas. A normalidade foi aferida através do teste de Kolmogorov-Smirnov. Como resultado, o $p$ de todos os constructos foi equivalente a 0,000 , dessa forma podemos afirmar que os dados não correspondem a uma distribuição do tipo normal e, portanto, a avaliação precisa ser realizada através de estatística não paramétrica. Assim a comparação entre as diferentes medianas foi obtida através do teste de Wilcoxon. O resultado está expresso na Tabela 4. 
TABELA 4 - Teste de Wilcoxon para os constructos motivacionais

\begin{tabular}{l|c|c}
\hline \multicolumn{1}{c|}{ Constructos } & $\mathbf{Z}$ & p (2 extremidades) \\
\hline Desmotivação $\times$ Externa & $-5,582$ & 0,000 \\
\hline Desmotivação $\times$ Introjetada & $-0,845$ & 0,400 \\
\hline Desmotivação $\times$ Identificada & $-9,059$ & 0,000 \\
\hline Desmotivação $\times$ Integrada & $-7,651$ & 0,000 \\
\hline Desmotivação $\times$ Intrínseca & $-7,902$ & 0,000 \\
\hline Externa $\times$ Introjetada & $-6,040$ & 0,000 \\
\hline Externa $\times$ Identificada & $-10,103$ & 0,000 \\
\hline Externa $\times$ Integrada & $-9,491$ & 0,000 \\
\hline Externa $\times$ Intrínseca & $-9,629$ & 0,000 \\
\hline Introjetada $\times$ Identificada & $-9,609$ & 0,000 \\
\hline Introjetada $\times$ Integrada & $-8,477$ & 0,000 \\
\hline Introjetada $\times$ Intrínseca & $-8,318$ & 0,000 \\
\hline Identificada $\times$ Integrada & $-4,075$ & 0,000 \\
\hline Identificada $\times$ Intrínseca & $-3,618$ & 0,000 \\
\hline Intrínseca $\times$ Integrada & $-0,965$ & 0,335 \\
\hline
\end{tabular}

Fonte: os autores.

A partir do cálculo do teste de Wilcoxon podemos afirmar que não há diferença significativa entre dois pares, são eles:

-Desmotivação com a Regulação Introjetada;

-Motivação Intrínseca com a Regulação Integrada.

Por conseguinte, há diferença significativa entre os demais pares, o que corrobora a discussão já iniciada.

Os dados obtidos e apresentados na Tabela 3 nos levam a crer que os estudantes do curso de Licenciatura em Química da Universidade de Brasília não se encontram desmotivados para se tornarem docentes. A maior parte das respostas para esse constructo foi situada nas marcações inferiores, o que nos leva a acreditar que a chance desses alunos evadirem, em condições normais, é baixa, embora não seja inexistente. Questões como "Eu continuo na licenciatura, mas estou infeliz no curso" foram irrisoriamente pontuadas.

Reguladores Externos também foram situados abaixo da média da escala. Assim, podemos afirmar que os estudantes não continuam na licenciatura em razão da presença de ameaças ou recompensas de agentes, como um familiar, por exemplo. Respostas pontuadas minimamente como a questão "Eu curso licenciatura porque sofro uma pressão externa 
para prosseguir" nos levam a inferir que o estudante não se encontra sob coação para ser docente.

Uma das pressões que poderia acontecer em cidades como Brasilia, refere-se à questão financeira, pois, embora o salário docente não seja proeminente de modo geral, o Distrito Federal tem uma realidade diferenciada. Conforme visto na Figura 4, ocupa $\circ 6^{\circ}$ lugar em relação ao piso salarial, portanto está entre os maiores do País.

No que tange a regulação introjetada, os valores também foram baixos. Em vista disso, podemos afirmar que os estudantes não se sentem pressionados a continuar no curso por questões relacionadas à sua consciência. Afirmações como "Eu continuo na licenciatura para provar a mim mesmo que sou capaz de completar o curso" tiveram um baixo score. Assim, a pressão interna para continuar no curso, se existe, não se mostrou proeminente.

Diante das medianas obtidas, surgiu a hipótese de estarmos frente a frente a um grande grupo composto pela Desmotivação, Regulação Externa e Regulação introjetada. Essa possibilidade foi confirmada com a construção dos histogramas de cada constructo como pode ser visualizado na Figura 6.

FIGURA 6 - Histograma da Desmotivação, Regulação Externa e Regulação Introjetada

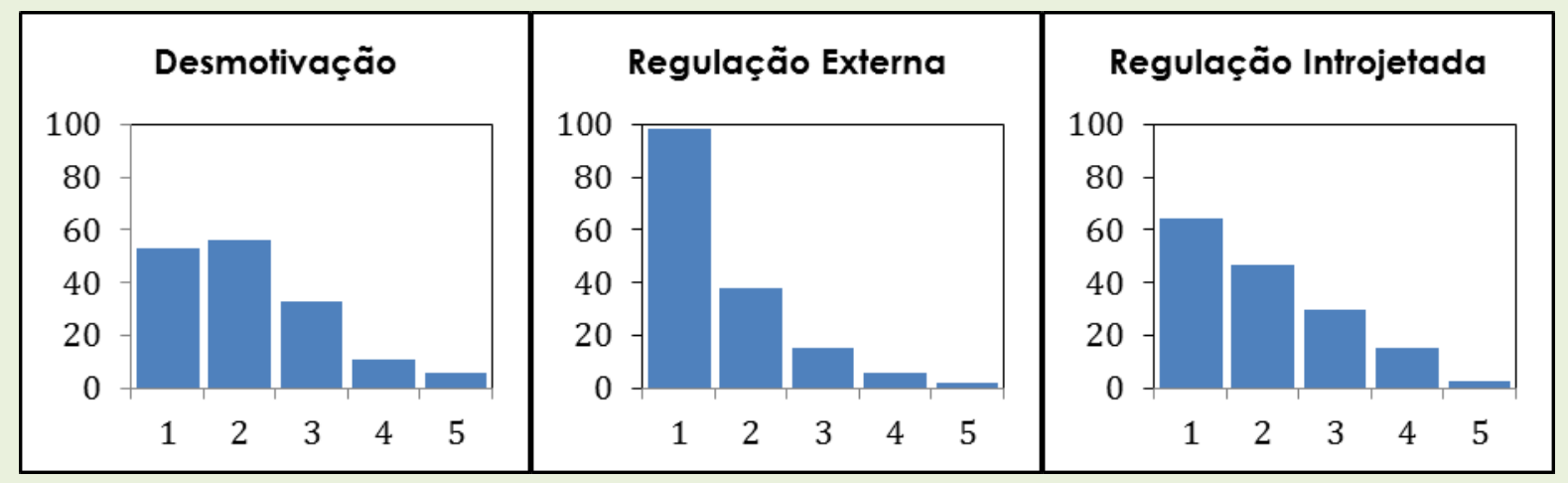

Fonte: os autores.

Esse grupo apresenta os níveis menos autorregulados do continuum e indicam a baixa frequência de pressões internas ou externas para 
continuarem na licenciatura. Sendo assim, podemos dizer que esses dados são positivos, pois saber que os alunos não estão no curso por coações internas ou externas é tranquilizante diante do cenário caótico que estamos vivenciando. Caso o fosse, estaríamos em uma iminência de vivenciar um apagão da Licenciatura em Química na Universidade de Brasília. Afinal, a perspectiva não é nada animadora com os contínuos "contingenciamentos" e "suspensões" financeiras (JUCÁ, 2019), os quais apontam para uma tentativa de desmonte da educação pública como evidenciado no projeto Future-se (TENENTE, 2019).

Um segundo grupo pode ser formado pela regulação identificada, integrada e intrínseca (Figura 7). Esses são os níveis mais autorregulados do continuum e estão preponderantemente com o score mais pronunciado do que o primeiro grupo.

FIGURA 7 - Histograma da Regulação identificada, Integrada e Motivação intrínseca

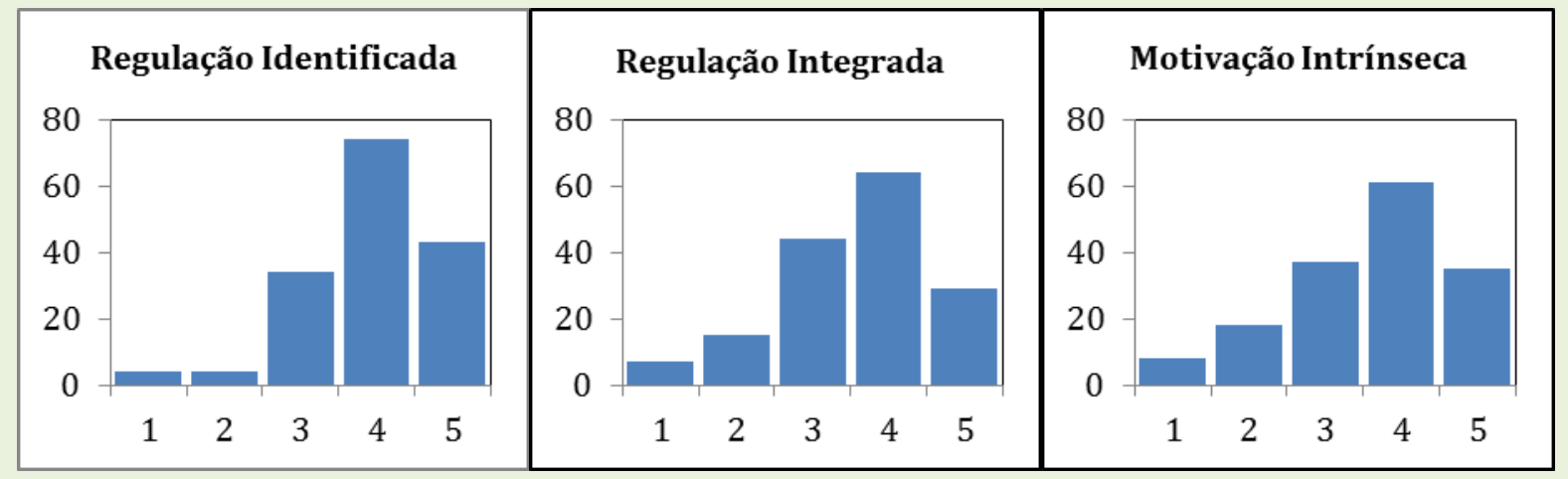

Fonte: os autores.

A regulação identificada merece especial atenção, pois foi o fator mais proeminente refere-se à percepção de importância da profissão docente. As respostas a questões como "Eu curso licenciatura porque eu considero que professor é uma profissão importante" nos levam a crer que nossos estudantes reconhecem o papel da docência na construção da sociedade e percebem que nesse lugar de fala poderão ter papel relevante na edificação do mundo que desejam. Não estamos afirmando que esse mundo almejado pelos nossos discentes é melhor ou pior do que o 
vivenciado, afinal afirmações como essa dependem de respostas a questões que não foram analisadas neste trabalho, como a compreensão de bem e mal, percepção sobre direitos humanos entre outros fatores.

A regulação integrada também apresentou valores proeminentes, fato este inesperado, pois ao retratar questões como "Eu curso licenciatura porque eu sinto que nasci pra ser professor" ou "Ser professor reflete quem eu sou" referem-se a uma percepção sobre o self do indivíduo. Dessa forma, imaginávamos valores menos pronunciados tendo em vista a baixa idade dos sujeitos. Desse modo, perceber que nossos alunos enxergam a docência com um sentimento de missão de vida reforça nossa expectativa nesses jovens como agentes transformadores que, a depender de como forem formados, podem contribuir para a construção de uma sociedade mais humana.

A motivação intrínseca expôs valor elevado indicando que nossos alunos sentem prazer com a docência, como pode ser exemplificado pelos altos scores de questões como "Eu curso licenciatura porque sinto prazer quando estou realizando atividades específicas da Licenciatura". O sentimento de prazer relatado por nossos estudantes indica que dificilmente eles irão desistir do curso.

Dessa forma, a partir dos valores encontrados, podemos afirmar que os estudantes do curso de Licenciatura em Química da Universidade de Brasília têm como motivação para serem docentes questões autorreguladas, principalmente, a percepção de que o magistério é importante. Eles também enxergam a docência como parte da missão de vida além de sentirem prazer nas atividades específicas do curso. Em vista disso, podemos afirmar que a opção por Ser Professor é, para esses estudantes, de fato, uma opção e não a falta de uma. Não estamos afirmando que os estudantes irão concluir o curso ou que com certeza seguirão a carreira docente, tão pouco que terão um futuro de felicidade, mas podemos acreditar que hoje essa escolha, em permanecer na licenciatura, é uma decisão autorregulada. Situações adversas e extremas, no entanto, podem ocorrer nos próximos semestres e alterar significativamente a decisão desses jovens. 
Essas situações tormentosas podem ocorrer não apenas dentro do curso, mas já no exercício da docência. Como exposto por Souto (2016), muitos professores acabam abandonando a carreira por causa de inúmeras frustrações oriundas da vivência na profissão. Essa quebra nas expectativas já havia sido relatada como o choque entre os ideais construídos durante a formação e a realidade experimentada no cotidiano (PACHECO, FLORES, 1999 apud FERREIRA, KASSEBOEHMER, 2012).

Embora os autores falem sobre ideais construídos durante a formação, não podemos esquecer a estereotipização vendida pela indústria cinematográfica que coloca o docente como um grande Super Herói que revolucionará a Escola e o Sistema lutando contra tudo e todos (SOUZA, 2007). Essa frustração com a realidade idealizada empurra os professores, muitas vezes, para o conformismo da luta pela sobrevivência (FERREIRA, KASSEBOEHMER, 2012) e quem poderá culpá-los?

Essa reflexão nos leva a pensar que um caminho, emocionalmente responsável, que nos distancia do estereótipo do professor herói, na luta contra a evasão, é trazer situações que reforcem o sentimento de importância da profissão docente sem omitir as dificuldades do cotidiano. Essa ação pode ocorrer, por exemplo, através de convites a professores já em exercício para relatarem suas experiências na sala de aula. Esses podem dissertar sobre como o exercício da docência impactou a vida dos discentes e da comunidade onde estão inseridos, não omitindo as dificuldades enfrentadas. Além disso, os próprios alunos, por meio de atividades como Rodas de Conversa podem dialogar sobre o impacto de algum docente e/ou da Escola na sua vida sob as mais diversas perspectivas. Situações como essas podem acontecer em parceria com estudantes de programas de mestrado profissional em Ensino, pois seria um caminho para conectar os dois públicos favorecendo a consolidação da identidade do curso.

Achamos importante fazer um destaque sobre a necessária responsabilidade emocional na implementação de atividades que visem fortalecer a percepção de importância da docência. Afinal, o reforço do estereótipo de professor salvacionista pode levar nossos discentes ao 
adoecimento mental. A fim de auxiliar nossa reflexão, solicitamos à Secretaria de Saúde do Distrito Federal, por meio da Lei no 12.527/2011 (BRASIL, 2011) que garante o direito ao acesso à informação pública, dados referentes ao perfil de absenteísmo ocasionado por doença dos servidores estatutários da Secretaria de Estado de Educação com o respectivo CID (Classificação Estatística de Doenças e Problemas Relacionados com a Saúde) referente ao ano de 2018.

Assim, com os dados fornecidos pudemos constatar que para os $27 \mathrm{mil}$ servidores ativos do magistério público do DF, aproximadamente 23 mil licenças foram concedidas. Aproximadamente $29 \%$ ocasionadas por transtornos mentais e comportamentais, o que correspondeu a cerca de $40 \%$ dos dias afastados.

Embora estejamos analisando o Ser Docente no Distrito Federal, precisamos refletir se essa conjectura não é uma questão nacional. Arcoverde et al (2017), também por meio da lei de acesso a informação, atestaram que em São Paulo o afastamento de professores da educação básica saltou de 25 mil em 2015 para aproximadamente 50 mil em 2016, o que representava cerca de $37 \%$ do total de licenças.

Diante desse cenário, não é intenção nossa levar para a sala de aula uma realidade assustadora, mas é importante pensarmos em ações que permitam que os alunos do curso de licenciatura possam ter contato com professores da educação básica e seus relatos de sucesso e insucesso para que tenham uma visão menos romantizada do ensino, mas que também não sejam submersos em pessimismo. Portanto, não estamos dizendo que será necessário minar a vontade de transformar o mundo, estamos dizendo que é preciso trazer um discurso sobre a realidade a fim de prepará-los para o que é a carreira docente, destituindo-os das fantasias de modo a não limitar a formação de professores às questões do processo de ensinoaprendizagem. Precisamos contribuir com a saúde mental da nossa sociedade e esse pode ser um caminho inicial.

Essa questão de adoecimento mental não é novidade na sala de aula. Na década de 1970, nos Estados Unidos, foi identificada a síndrome de 
burnout (em português, síndrome da desistência) que, se refere à perda de energia para lidar com pessoas e trabalho por causa de uma exaustão incapacitante. A síndrome da desistência tem sido presença constante entre os profissionais da educação (SOUZA, 2007).

Ademais, os dados também foram submetidos à análise de correlação a fim de verificar a contribuição de um constructo em relação a outro e a possibilidade de existência concomitante. Para isso foi calculado, primeiramente, com o teste Kolmogorov-Smirnov, se os valores descrevem uma distribuição normal. Todas as significâncias foram equivalentes a 0,000. Dessa forma, a não normalidade constatada demandou o cálculo não paramétrico do coeficiente de Spearman. As correlações obtidas podem ser verificadas na Tabela 5.

A correlação, de acordo com Cohen (1988) apud Clarck e Schroth (2010), será considerada fraca quando menor do que 0,3 , moderada caso esteja entre 0,3 e 0,5, e forte para valores acima de 0,5.

TABELA 5 - Matriz de correlação dos constructos fazendo uso do coeficiente de Spearman

\begin{tabular}{l|l|l|l|l|l|l}
\hline & Desmotivação & $\begin{array}{l}\text { Regulação } \\
\text { Externa }\end{array}$ & $\begin{array}{l}\text { Regulação } \\
\text { Introjetada }\end{array}$ & $\begin{array}{l}\text { Regulação } \\
\text { Identificada }\end{array}$ & $\begin{array}{l}\text { Regulação } \\
\text { Integrada }\end{array}$ & $\begin{array}{l}\text { Motivação } \\
\text { Intrínseca }\end{array}$ \\
\hline Desmotivação & 1,0 & 1,00 & & & & \\
\hline $\begin{array}{l}\text { Regulação } \\
\text { Externa }\end{array}$ & 0,4 & 0,4 & 1,0 & & & \\
\hline $\begin{array}{l}\text { Regulação } \\
\text { Introjetada }\end{array}$ & 0,4 & $-0,3$ & 0,0 & 1,0 & & \\
\hline $\begin{array}{l}\text { Regulação } \\
\text { Ilentificada }\end{array}$ & $-0,4$ & $-0,3$ & $-0,0$ & 0,3 & 1,0 & \\
\hline $\begin{array}{l}\text { Regulação } \\
\text { Integrada }\end{array}$ & $-0,4$ & $-0,3$ & $-0,1$ & 0,3 & 0,6 & 1,0 \\
\hline $\begin{array}{l}\text { Motivação } \\
\text { Intrínseca }\end{array}$ & $-0,4$ & & & & & \\
\hline
\end{tabular}

Fonte: $\mathrm{o}$ autor.

Podemos perceber na Tabela 5 que as motivações não são excludentes, podendo coexistir várias e em distintos níveis de intensidades, porém sempre deslocada para um lado ou outro do continuum a depender de um fator predominante.

Ademais, as correlações encontradas, de forma geral, situam-se no nível moderado sendo que os fatores do grupo 1, por nós definido como 
grupo que contém a Desmotivação, a Regulação Externa e a Regulação Introjetada, correlacionam-se positiva e moderadamente entre si. Porém, quando analisamos a correlação desses fatores com os pertencentes ao grupo 2 (Regulação Identificada, Regulação Integrada e Motivação Intrínseca), percebemos correlação moderadamente negativa. As correlações encontradas do grupo 2 com o próprio grupo 2 situam-se entre o nível moderado e forte positivamente.

Essas correlações indicam que estar motivado em um dos dois grupos favorece a motivação do mesmo grupo enquanto desnutre a regulação do grupo oposto, ou seja, um estudante que tenha motivação para ser professor por meio da regulação externa, nutrirá moderadamente a sua regulação introjetada assim como a desmotivação, enquanto mina a regulação identificada, integrada e intrínseca.

Dessa forma, pressões internas e externas, cobranças em demasia para continuar no curso podem minar ainda mais o prazer em estar no ambiente docente, o que conduz nossos discentes à desmotivação e, possivelmente, à evasão, sendo, portanto, pela análise de nossos dados, fortemente contraindicadas.

Assim, na luta contra evasão, consideramos que é imprescindível auxiliarmos os alunos da licenciatura a desenvolverem a motivação identificada porque:

1) É a que possui o mais baixo nível dentre as mais autorreguladas do grupo 2 no continuum motivacional e por isso é a mais acessível às atividades externas;

2) Irá nutrir a regulação integrada e a motivação intrínseca auxiliando os estudantes a sentirem prazer no exercício da docência;

3) Irá afastar nossos estudantes da desmotivação, da regulação externa e introjetada.

Em vista disso, atividades que façam com que os alunos enxerguem o poder da educação podem ser transformadoras não apenas por fortalecer a regulação identificada, mas auxiliar o estudante a sentir prazer com a 
docência e embebidos de prazer possam mais do que resistir, possam lutar por uma docência humanizada.

\section{Conclusão}

As análises estatísticas dos dados obtidos mostram que o questionário proposto é um bom instrumento para estudar o que motiva os discentes do curso de Licenciatura em Química a serem docentes.

De acordo com os valores obtidos, as razões principais situam-se no mais alto nível de regulação com destaque para a percepção de importância da profissão docente. Notou-se que tal regulação, além de ser a mais proeminente, se correlaciona positivamente com a regulação integrada e motivação intrínseca, além de se correlacionar negativamente com a regulação introjetada, externa e com a desmotivação. Portanto, apontamos como um caminho, na luta contra a evasão acadêmica e desenvolvimento da motivação intrínseca, a realização de atividades que ressaltem, de forma emocionalmente responsável, a importância do professor para a construção da sociedade. Acreditamos que, dessa forma, podemos formar professores motivados e aptos a lidarem com as adversidades inerentes à profissão e ao contexto atual.

\section{AGRADECIMENTO}

Ao Decanato de Ensino de Graduação-DEG da Universidade de Brasília pelo apoio financeiro através do EDITAL DEG/DAC N 11/2017.

Ao Instituto de Química da UnB e ao PET-QUI/UnB PET/SeSU/MEC pelos recursos humanos.

\section{REFERÊNCIAS}

ALMEIDA, C. Concluir o ensino superior triplica a renda, mostra IBGE. O Globo, 14/04/2018. Disponível em: < https://oglobo.globo.com/economia/concluirensino-superior-triplica-renda-mostra-ibge-22579344>. Acesso em: 26/09/2019.

ARAUJO, N. R. S.; LABURÚ, C. E. Uma análise da validação e confiabilidade da escala de opiniões da seleção de experimentos de química (EOSEQ).

Ensaio-Pesquisa em Educação em ciências, v.1 1, n.2, p.199-220, 2009. 
ARCOVERDE, L.; FRANCO, E.; GALVÃO, D.; PRADO, G. Número de professores afastados por transtorno em SP quase dobra em 2016 e vai a 50 mil. Globo News, São Paulo. 21/11/2017. Disponível em <https://gl.globo.com/sp/saopaulo/noticia/numero-de-professores-afastados-por-transtornos-em-spquase-dobra-em-2016-e-vai-a-50-mil.ghtml>, Acesso em:15/10/2018.

ARIANI, D. W. Personality and Learning Motivation. European Journal of Business and Management. v.5, n.10, p.26-39, 2013.

BERNADO, M. V. C. O surgimento e a trajetória da formação do professor secundário nas universidades estaduais paulistas. In: BERNADO, M. V. C. Formação do professor: atualizando o debate. São Paulo: EDUC, 1989. p. 11 62.

BORUCHOVITCH, E; BZUNECK, J. A. A motivação do aluno: contribuições da psicologia contemporânea. 4a Edição. Petrópolis: Editora Vozes. 2009.

BORUCHOVITCH, E. BZUNECK, J. A.; GUIMARÃES, S. E. R. Motivação para aprender: aplicações no contexto educativo. Petrópolis: Editora Vozes. 2010.

BRASIL. Ministério da Educação. Conselho Nacional de Educação/Conselho Pleno. Resolução n1, de 18 de fevereiro de 2002.

BRASIL. Lei no 12.527, de 18 de novembro de 2011. Regula o acesso a informação. Disponível em: < http://www.planalto.gov.br/ccivil_03/_Ato201 12014/2011/Lei/L12527.htm>.

BRASIL. Ministério da Educação. Conselho Estadual de Educação. Resolução no 111, de 15 de março de 2012.

BRASIL, Ministério da educação Conselho Nacional de Educação/ Conselho Pleno. Resolução n², de 1 de julho de 2015.

BRASIL, Instituto Brasileiro de Geografia e Estatística. Resolução n², de $\mathbf{2 8}$ de agosto de 2018. Disponível em:

$<$ http://pesquisa.in.gov.br/imprensa/jsp/visualiza/index.jsp?jornal=515\&pagin $a=55 \&$ data $=29 / 08 / 2018>$. Acesso em: 22/09/2019.

CLARCK, M. H.; SCHROTH, C. A. Examining relationships between academic motivation and personality among college students. Learning and individual differences. V.20, n.1, p.19-24, 2010.

CUNHA, A. M.; TUNES, E.; SILVA, R. R. Evasão do curso de química da universidade de Brasília: a interpretação do aluno evadido. Química Nova. v. 24, n. 1, p.262-280, 2001. 
DECl, E. L.; RYAN, R. M. Intrinsic motivation and self-determination in human behavior. New York: Plenum Press, 1985.

FERREIRA, L.H.; KASSEBOEHMER, A.C. Formação inicial de professores de química: a instituição formadora (re) pensando sua função social. São Carlos: Pedro \& João Editores, 2012.

FREIRE, P. Pedagogia da autonomia: saberes necessários à prática educativa. São Paulo: Editora Paz e Terra, 1996.

FREIRE, P. Professora sim, tia não: cartas a quem ousa ensinar. São Paulo: Olho d'água, 1997.

FREITAS, A. L. P.; RODRIGUES, S. G. A avaliação da confiabilidade de questionários: uma análise utilizando o coeficiente alfa de Cronbach. In: SIMPEP. 12, 2005, Bauru. Anais... Bauru: Universidade Estadual Paulista, 2005.

GATTI, B. A. A formação inicial de professores para a educação básica: as licenciaturas. Revista USP. n.100, p.33-46, 2014.

GATTI, B. A; BARRetTO, E. S. de S.; ANDRÉ, M. E. D. A. Políticas Docentes no Brasil: um Estado da Arte. Brasília: Unesco, 2011.

GUIMARÃES, S. É. R. Avaliação do estilo motivacional do professor: adaptação e validação de um instrumento. 2003. 188f, Tese (Doutorado em Educação)- Universidade Estadual de Campinas. Campinas/SP, 2003.

HUCK e FARO menosprezam professores em campanha, dizem seguidores. Catraca Livre, 18/08/2017. Disponível em <https://catracalivre.com.br/educacao/huck-e-faro-menosprezamprofessores-em-campanha-dizem-seguidores/>. Acesso em: 26/09/2019.

Instituto Brasileiro de Geografia e Estatística- Síntese de indicadores sociais: uma análise das condições de vida da população brasileira, Rio de Janeiro: IBGE, 2018.

INSTITUTO NACIONAL DE ESTUDOS E PESQUISAS EDUCACIONAIS ANÍSIO TEIXEIRA. Censo da educação superior 2018: notas estatísticas. Brasília: Inep, 2019. Disponível em: <http://portal.inep.gov.br/web/guest/censo-daeducacao-superior $>$. Acesso em: 21/09/2019.

JUCÁ, B. Cortes de verbas desmontam ciência brasileira e restringem pesquisa a mais ricos. El Pais, São Paulo, 09/09/2019. Disponível em < https://brasil.elpais.com/brasil/2019/09/03/politica/1567542296_718545.html>. Acesso em: 20/09/2019. 
NOSELLA, P. A formação do educador e do professor: esboço históricofilosófico. In: NOSELLA, P.; JARDILINO, J.R.L. Os professores não erram: ensaio de história e teoria sobre a profissão de mestre. São Paulo: Pulsar, 2005, p.2372.

REEVE, J. Motivação \& Emoção. 4a edição. Rio de Janeiro: LTC, 2006.

ROSA, H. Professores e garçons estão entre os bicos mais buscados. Metro, Campinas, 30/05/2016. Disponível em< https://www.readmetro.com/en/brazil/metrocampinas/20160530/8/\#book/8>. Acesso em: 07/08/ 2019.

SANTIAGO, A. 2019. Mesmo em crise, estados pagam acima do piso para professores; veja ranking. Gazeta do povo, 04/04/2019. Disponível em: < https://www.gazetadopovo.com.br/educacao/mesmo-em-crise-estadospagam-acima-do-piso-para-professores-veja-ranking/>. Acesso em: 26/09/2019.

SOUTO, R. M. A. Egressos da licenciatura em matemática abandonam o magistério: reflexões sobre profissão e condição docente. Educação e Pesquisa, v. 42, n.4, p.1077-1092, 2016.

SOUZA, J. V. A. (Org). Formação de professores para a Educação Básica: dez anos da LDB. Belo Horizonte: Autêntica, 2007.

TAKAHASHI, F. Após pressão, formação de professor terá menos teoria e mais aula prática. Folha de São Paulo. 28/10/2015. Disponível em: < https://www l.folha.uol.com.br/educacao/2015/10/1699449-apos-pressaoformacao-de-professor-tera-menos-teoria-e-mais-aula-pratica.shtml>. Acesso em: 18/09/2019.

TENENTE, L. Entenda o que já se sabe sobre o Future-se e o que ainda falta esclarecer. G1. 03/08/2019. Disponível em:

<https://gl.globo.com/educacao/noticia/2019/08/03/entenda-o-que-ja-sesabe-sobre-o-future-se-e-o-que-ainda-falta-esclarecer.ghtml>. Acesso em: 26/09/2019.

TOLEDO, E.J.L. Estudo da correlação entre motivação, estilo de aprendizagem e os tipos psicológicos junguiano. 2015. 132f, Tese (Doutorado em Química) - Universidade Federal de São Carlos, São Carlos/SP, 2015.

Recebido em: 04 de outubro de 2019

Aprovado em: 13 de janeiro de 2020 